\title{
Reliability-based optimization for energy refurbishment of a social housing building
}

\author{
Marco Manzan ${ }^{1}$, Giorgio Lupato ${ }^{1}$, Amedeo Pezzi ${ }^{1}$, Paolo Rosato ${ }^{1}$, Alberto Clarich ${ }^{2}$ \\ ${ }^{1}$ University of Trieste, Department of Engineering and Architecture, via A. Valerio 10, 34127, \\ Trieste, Italy \\ ${ }^{2}$ ESTECO S.p.A, AREA Science Park, Padriciano 99, 34149, Trieste, Italy
}

\begin{abstract}
This paper investigates the influence of a stochastic variation of economic parameters in an optimization loop applied to a refurbished social housing building. Usually energy and economic optimization procedures rely on the results of an underlying numerical deterministic model which influences both energy gains and economic figures. However, the results are influenced by parameters, which cannot be known in advance especially if they can change during a long period, such as fuels cost and economic indexes. To overcome the problem in this paper a robust approach for building refurbishment optimization has been adopted. Robust optimization considers a stochastic variation of parameters looking for solutions that are not only optimal but also robust, that is the optimal solutions maintaining the optimality also for a range of the input parameters. The considered building represents a social house, and the energy reduction measures involve the application of internal insulation layers to the walls and the replacement of existing windows with more efficient ones.
\end{abstract}

\section{Introduction}

The energy consumption in residential sector in Italy covers $36 \%$ of the national final energy use, a large amount especially if compared to the transport, sector that absorbs $32 \%$, and the industrial one, responsible of the $23 \%$ share. Furthermore, the highest share of energy in residential sector is due to building heating, especially in northern Italy, due to the age of the buildings with poor building fabric and insulation characteristics.

Italy is committed in reducing energy consumption limiting emissions with an undoubtable benefit to the environment and citizen's health.

Large efforts have been conducted in order to increase plant efficiencies, especially with the substitutions of old boilers with newer condensing ones, and the exploitation of renewable energy sources. To extend the process important investments should be focused on refurbishment activities too. However, when an operator tackles the refurbishment of existing buildings, it faces the problem of large investment costs which can become a limiting factor, in this case investors should carefully perform risk assessment for each intervention.

The task is clearly multidisciplinary and involves both accurate energy and economic analysis, in order to define a suitable approach.
Energy simulation techniques are nowadays widespread; they allow previewing the effect of energy refurbishment efforts and the results are also the base to perform cost evaluation procedures. For example, the beneficial effect of subsidies are highlighted by Desogus (2013), he compares the economic feasibility of different energy efficiency retrofits for social houses.

The energy retrofit of a building is a typical case where different solutions characterized by a great number of parameters should be taken into account at the same time. In this case in literature optimization techniques are gaining great interest since they allow to restrict the possible solutions to an optimal subset based on specified goals. When dealing with building refurbishment one of the optimization goals takes into account the economic feasibility of the intervention, driving the users to select solutions with a suitable trade-off between the energetic and economic perspectives. As an example, Ascione et al. (2015) searched optimal solutions for building refurbishment taking into account both energy and the costs of the intervention. Lupato (2018) and al. highlighted the effect of climatic data on the results of an optimization loop for the refurbishment of a social house, they used as objectives the overall energy consumption and the present net value of the investment. Manzan et al (2016) followed a similar approach, while taking into account also the effect of subsidies.

Usually optimization techniques apply a deterministic approach, fixing some parameters, while changing others during the optimization process. However, while dealing with economic analysis, it is common to incur in situations where parameters are not under control and can vary during the time, especially with long building's lifetime. In order to introduce this approach into an optimization process, uncertainty in searching optimal designs should be added to the process. This is even more important in a refurbishment process, where an investor requires not only a cost analysis, but also must evaluate the economic risk intrinsic in each investment.

Some authors point out the requirement to analyse the effect of uncertain parameters in building simulation. Sun et al. (2016) used a probabilistic method for risk assessment in computing the energy requirement and utility cost using a reference commercial building; they computed mean values and standard deviation for identifying the risk associated with a project. Chari (2017) performed a stochastic assessment of the energy 
performance of buildings considering 12 different regions in Europe identifying the factors with the greatest impact on energy use. Prada (2018) analysed the uncertainty propagation of the material properties in energy simulations emphasizing the problem of a correct assessment of physical properties in existing buildings in order to optimize energy refurbishment. Di Giuseppe (2017) worked on a case study for performing a sensitivity analysis and identified the main parameters affecting the Life Cycle Cost of a building. The research identified the financial factors, inflation, discount rate and the energy trend uncertainty as the most influential parameters.

While in literature sensitivity analysis of energy building simulation is a well established field of research, less studied is the effect of uncertainty on optimization. Cano (2016) applied a stochastic multi-staged optimization algorithm highlighting the requirement to introduce stochastic variables for risk assessing and decision making.

In this work the refurbishment of an existing building is considered; optimal solutions are searched considering two objective functions related to the energy performance and economic feasibility of the intervention. With the aim of developing a method to support potential investors, uncertainties have been embedded into the numerical process.

\section{Building description}

An existing building in Trieste, a city in north - east Italy, was chosen to run the robust optimization, and the main features are described by Lupato (2018). It is composed by four blocks with apartments adjacent to each other. Every block is formed by four floors with two small flats each. The ground floor apartments consist of a kitchen, a bathroom and a bedroom. Every level above the ground floor features two apartments that contain one and two bedrooms respectively, a bathroom and a kitchen. The ground level floors and the third level ceilings are adjacent to aerated spaces. The base building was built with massive structures without insulation. The energy refurbishment has been carried on by adding insulating layers to the internal vertical and horizontal surfaces in order to preserve the facades. A total of five types of flats have been identified; Table 1 presents the percentage of area characteristic for each one.

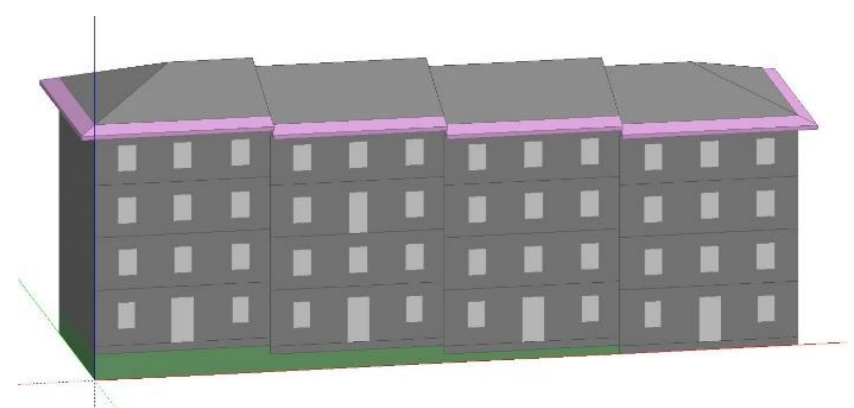

Figure 1: Model image.
Table 1: distribution of the spaces for each flat.

\begin{tabular}{|c|c|c|}
\hline Configuration & $\begin{array}{c}\text { Living Room }+ \\
\text { Kitchen }\end{array}$ & $\begin{array}{c}\text { Other Conditioned } \\
\text { Spaces }\end{array}$ \\
\hline Apt 1 & $34,00 \%$ & $66,00 \%$ \\
\hline Apt 2 & $30,00 \%$ & $70,00 \%$ \\
\hline Apt 3 & $26,00 \%$ & $74,00 \%$ \\
\hline Apt 4 & $28,00 \%$ & $72,00 \%$ \\
\hline Apt 5 & $31,00 \%$ & $69,00 \%$ \\
\hline
\end{tabular}

Table 2: distribution of internal gains.

\begin{tabular}{|c|c|c|c|c|c|c|}
\hline \multirow[t]{2}{*}{ Day } & \multirow[t]{2}{*}{ Hours } & \multicolumn{5}{|c|}{ Flat type } \\
\hline & & 1 & 2 & 3 & 4 & 5 \\
\hline \multirow{3}{*}{$\begin{array}{c}\text { Monday } \\
- \\
\text { Friday }\end{array}$} & $\begin{array}{c}07: 00 \text { to } \\
17: 00\end{array}$ & 3.38 & 3.10 & 2.82 & 2.96 & 3.17 \\
\hline & $\begin{array}{c}17: 00 \text { to } \\
23: 00\end{array}$ & 7.46 & 6.70 & 5.94 & 6.32 & 6.89 \\
\hline & $\begin{array}{c}23: 00 \text { to } \\
07: 00\end{array}$ & 4.64 & 4.80 & 4.96 & 4.88 & 4.76 \\
\hline \multirow{3}{*}{$\begin{array}{c}\text { Saturday } \\
- \\
\text { Sunday }\end{array}$} & $\begin{array}{c}07: 00 \text { to } \\
17: 00\end{array}$ & 4.04 & 3.80 & 3.56 & 3.68 & 3.86 \\
\hline & $\begin{array}{c}17: 00 \text { to } \\
23: 00\end{array}$ & 9.44 & 8.80 & 8.16 & 8.48 & 8.96 \\
\hline & $\begin{array}{c}23: 00 \text { to } \\
07: 00\end{array}$ & 4.64 & 4.80 & 4.96 & 4.88 & 4.76 \\
\hline
\end{tabular}

\section{Building model description}

A stochastic approach is usually time consuming, requiring a large amount of computational resources, since for each design several additional simulations should be performed. In the present work the uncertainties have been added to economic indexes only; this decouple the problem into deterministic energy computation and stochastic economic analysis. However, with the aim to introduce in future uncertainties in the energy analysis, a simplifying approach has been used for building's modelling in order to speed up the computation.

The partition of interior spaces has been simplified. Every single apartment has been modelled as a unique space while keeping partitions between each other and between apartments and common spaces. However, in order to consider the physical presence of the partitions inside each apartment, equivalent internal masses were added to assure the correct thermal inertia to the system.

Internal gains due to people and equipment follow the pattern for residential buildings of EN ISO 13790.

The internal gains defined by the standard EN ISO 13790 were weighted through the percentage areas shown in Table 1 to obtain the total internal gain for every type of apartment, as presented in Table 2. However, the values reported in Table 2 consider the presence of the people too. The people has been inserted in the model considering two metabolic activities: sleeping condition, with $85 \mathrm{~W} /$ person and light working, with $110 \mathrm{~W} /$ person. The metabolic rates were multiplied by the number of persons, maximum two due to the size of the flats, to obtain people internal gains. These loads were subtracted from the internal ones reported in Table 2. No gains were 
modelled for entrances, circulation spaces and bathrooms Lighting gains were considered as included in internal gains.

Air infiltration has been computed in a simplified manner considering an air change rate $0.50 \mathrm{vol} / \mathrm{h}$ for each apartment.

Heating set-point temperature is $20^{\circ} \mathrm{C}$ from 7 am to $2 \mathrm{pm}$ and from $4 \mathrm{pm}$ to $11 \mathrm{pm}$. During the remaining time a setback temperature of $18^{\circ} \mathrm{C}$ was set.

The building blocks have a separate heating plant system which was modelled with an HVAC system composed of a gas boiler and water radiators as terminals in each flat.

Pumps were modelled as variable speed ones. According to Italian law for climatic zone E, the boiler availability was set from the 15th of October until the 15th of April. The heating system water temperature was modelled as modulating through outdoor air temperature sensor.

Circulation spaces and entrances were considered as unheated. Finally, no cooling system was considered.

The base building external wall is composed by two layers of full-bricks, each $25 \mathrm{~cm}$ thick. The ground floor, the roof and the third level ceilings present a concrete structure whose thickness varies from $15 \mathrm{~cm}$ to $22 \mathrm{~cm}$.

External fenestrations consist of a single-layer glass with high SHGC and thermal transmittance. Domestic hot water has not been included into the simulation, therefore energy consumption takes into account heating energy only.

\section{Reliability-based Design Optimization - Optimization under uncertainties}

Robust design optimization, or optimization under uncertainties, is achieving more and more agreement in the design practice. In fact, most of the human processes are permeated by uncertainties: the manufactured product is generally different, from a geometric point of view, from the design product because of the dimensional tolerances. In energy economics issues the parameters aren't fixed, but are characterized by some fluctuations that can change the problem outcome.

This uncertainty is commonly transferred to the performance of the system, which cannot be determined with an exact and single value, but which is better described by a statistical distribution of results.

In this environment, a frequent design requirement is the satisfaction of constraints or limits, which should be achieved for a specified percentage of the performance distribution, or for which the percentage of solutions not satisfying the limits, or failure probability, must be minimized as much as possible to improve the reliability and quality of the product (Clarich 2009). The same approach can be extended to energy building optimization, where different solutions must be compared, but where the design parameters can variate with a statistical distribution.

In literature, there are basically two types of approaches for this kind of problems.
The first one is the Robust Design Optimization (Clarich 2009, Kalsi 2001), which basically consists in evaluating, for each candidate design proposed by the optimization algorithm, the stochastic distribution of its performances, and in defining objectives based on mean and standard deviations of the same. For instance, maximize mean performances and minimize their standard deviations, in order to optimize the stability at the fluctuations. The strategy is particularly efficient, also because it may take advantage of Polynomial Chaos Expansion (Loeven 2007), an efficient methodology which exploits proper ortho-normal Polynomials to estimate analytically with high accuracy mean and standard deviation, through a reduced number of sampling evaluations.

The other approach followed in literature is the Reliability analysis which implements methodologies like FORM or SORM (Kiureghian 2005), which evaluate the failure probability of any candidate design on the basis of its uncertainties distribution and of the given limits to be respected. One limit of this methodology can be represented by the high number of evaluations that may be required by the algorithm to compute the failure probability with accuracy, which makes often practically unfeasible its application to optimization problems of industrial relevance.

For these reasons, we adopt in this paper an alternative procedure to deal efficiently with a reliability-based optimization problem, which conjugates accuracy and reduced number of needed evaluations.

The methodology takes advantage of the Polynomial Chaos Expansion, to evaluate the complete cumulative distribution function of the performances of the design, from which it is possible to accurately retrieve the probability of designs not meeting a goal for the prescribed objectives/constraints.

\section{Introduction to Polynomial Chaos Expansion}

In order to describe in a probabilistic way the response of a system subjected to uncertainties, one of the most efficient methodologies to be applied is the non-intrusive Polynomial Chaos Expansion (PCE) (Loeven 2007). By sampling the input uncertain parameters accordingly to their probabilistic distribution, the PCE regression model, described by Equation 1, allows to accurately compute the system performances probabilistic distribution $\Phi$, which is function of the input variables of the optimization problem $(\mathbf{x}, t)$, and of the uncertainties $\xi$, function of a random event $\theta$.

$$
\phi(x, t, \theta)=\sum_{i=0}^{\infty} \phi_{i}(x, t) \psi_{i}(\xi(\theta))
$$

In Eq. 1, the spectral expansion is given by the combination of particular Polynomials $\psi_{i}$ function of the uncertain variable $\xi$ and which are orthogonal to their corresponding distribution function: in the case of Normal distribution, the Polynomials are called Hermite Polynomials. For practical reasons, the series is normally truncated to a finite number of terms, which is function of 
the Polynomial order considered and of the number of uncertain parameters.

The unknown weight functions $\phi_{i}$ are computed for each design proposed by the optimization algorithm (x, $t$ being fixed), by the minimization of the regression error of the $\phi$ function computed by the sample points, evaluated accordingly to the distribution of the uncertain variables $\xi$.

\section{Definition of reliability-based optimization problem}

As anticipated above, in order to reduce the overall number of objectives, instead of the Robust Design approach, which requires optimizing mean and standard deviation of the response function separately, we applied the Reliability-based optimization approach. This approach consists in the minimization of the worst percentile of the performance distribution, min-max or max-min approach.

In the case of a Normal distribution of the performance, since it is unlimited, a given percentile of the distribution, for instance 90,95 or $99 \%$, may replace the concept of the extremes.

In order to reduce the computational load, the evaluation of the performance function is required only to determine the coefficients of the Polynomial Chaos Expansion, in the sampling phase. Once the coefficients are found, it is possible to express the CDF (cumulative distribution function) of any system response using directly the PCE polynomial, which can be considered as a meta-model of the response, practically free in terms of CPU load. Once the $\mathrm{CDF}$ is accurately obtained, we can easily retrieve the value corresponding to the needed percentile of the distribution, to define the objective to be minimized.

After a proper test of convergence on the baseline configuration, it has been decided that 40 samples and a second order Sparse PCE can give an accurate response. In this case the error on standard deviation of the performances has resulted to be less than $0.1 \%$, with respect to results obtained by using a large Monte Carlo database of 100 samples.

\section{Economic indexes and NPV computation of investment performances}

The evaluation of the economic performances of the proposed technological solutions was carried out with reference to the Net Present Value (NPV) of the flow of costs and savings generated by the various solutions, discounted at an appropriate discount rate $r$. The costs are essentially due to the investment $\left(C_{0}\right)$ necessary to implement the technological solutions considered and the savings are calculated from the differences $\left(S_{i}\right)$ between the current operating costs and those of the technological solutions. The operating costs refer to management, maintenance and energy consumption. Assuming an evaluation at constant prices, it is necessary to adopt a real discount rate $\left(r_{r}\right)$, removing the effect of inflation $\left(r_{i}\right)$ from the nominal value $\left(r_{\mathrm{n}}\right)$, using the following equation:

$$
r_{r}=\frac{r_{n}-r_{i}}{1+r_{i}}
$$

The net present value is given by:

$$
N P V=-C_{0}+\sum_{i=1}^{n} \frac{S_{i}}{\left(1+r_{r}\right)^{i}}
$$

Moreover, hypothesizing a constant $S_{i}$ Eq. 3 becomes:

$$
N P V=-C_{0}+S_{i} \frac{\left(1+r_{r}\right)^{n}-1}{r_{r}\left(1+r_{r}\right)^{n}}
$$

The economic performances assessment must take into account, in addition to the most likely values of the economic parameters, also their variability and the probable future trends of the main components of operating cost, energy first. Assuming equal to $r_{e}$, the real annual rate of increase in operating costs, Eq. 4 becomes:

$$
N P V=-C_{0}+S_{i} \frac{\left(\frac{1+r_{r}}{1+r_{e}}\right)^{n}-1}{\frac{r_{r}-r_{e}}{1+r_{e}}\left(\frac{1+r_{r}}{1+r_{e}}\right)^{n}}
$$

Rearranged as:

\begin{tabular}{|c|c|c|c|}
\hline Parameter & Value & Unit & Source \\
\hline Gas $(*)$ & 0,899 & $€ / \mathrm{m}^{3}$ & EUROSTAT \\
\hline $\begin{array}{c}\text { Electricity } \\
(*)\end{array}$ & 0,255 & $€ / \mathrm{kWh}$ & EUROSTAT \\
\hline $\begin{array}{l}\text { Inflation } \\
\text { rate }\left(r_{i}\right)(* *)\end{array}$ & 1,173 & $\%$ & $\begin{array}{c}\text { Worldwide } \\
\text { Inflation Data; } \\
\text { www.inflation.e } \\
\text { u }\end{array}$ \\
\hline $\begin{array}{l}\text { Discount } \\
\text { rate }\left(r_{n}\right)\end{array}$ & 4,090 & $\%$ & Bank of Italy \\
\hline $\begin{array}{c}\text { Energy } \\
\text { price trend } \\
\left(r_{e}\right)\end{array}$ & $\begin{array}{c}1,59 \\
\text { (s.d. } 1,40)\end{array}$ & $\%$ & $\begin{array}{c}\text { Energy } \\
\text { Information } \\
\text { Administration }\end{array}$ \\
\hline
\end{tabular}

$$
N P V=-C_{0}+S_{i} \frac{1+r_{e}}{r_{r}-r_{e}}\left[1-\left(\frac{1+r_{e}}{1+r_{r}}\right)^{n}\right]
$$

Table 3: economic parameters for the simulation.

(*) Mean last 10 years prices for household consumers all taxes and levies included

(**) Mean last 10 years

The simulation of the economic performances of the technological solutions considered was carried out assuming the values shown in Table 3 .

At first, in order to investigate the influence of stochastic variables, most of the economic parameters have been assumed constant and equal to the average of the values recorded in the last 10 years.

The only stochastic parameter introduced in the simulation is the future trend in the energy price, on which most analysts seem to converge.

An additional optimization has been subsequently carried on by assuming a stochastic behaviour of the investment cost $C_{0}$; this parameter should be known in advance however, as stated by Di Giuseppe et al. (2017), prices often change between the time of the design and final construction. 
The introduction of stochastic input variables obviously implies a stochastic output. In particular, the implemented optimization process presupposes the identification of a confidence limit to be associated with the stochastic objective to be optimized, in this case the NPV. Assuming a risk-neutral decision maker and a normal distribution of the NPV, the value to be optimized is the average or modal one. Normally, the decision maker is risk-averse and therefore optimizes a value with a probability to be overcame more than $50 \%$. Unfortunately, to our knowledge, there are no studies that have examined this aspect with reference to the energy requalification choices. Therefore, a very cautious attitude was assumed, hypothesizing a reference NPV with a probability of being exceeded by $90 \%$.

\section{Methodology}

The optimization was carried out with modeFRONTIER software. The program takes care of the whole optimization process performing also a robust optimization. In this case, some input variables are considered not as fixed values but following a probabilistic distribution. In this case also the outputs of the optimization process have a distribution that can be evaluated by the user.

In the present paper a reliability-based optimization has been performed by considering a normal distribution for the energy price increasing rate $r_{i}$; however, the inspection of Eq. 6 shows that this parameter has an effect on the NPV computation only. For instance, the energy gain obtained with the refurbishing activity can be computed once and used for performing a stochastic analysis on the NPV objective. This two-step approach lets the numerical solution with EnergyPlus to be carried once for design, while the reliability-based design optimization, or RBDO, can be performed in a fast way. modeFRONTIER allows to operate with nested projects so this capability has been exploited to carry on the optimization.

With reference to Figure 2, a Python script has been created in order to allow modeFRONTIER to drive the optimization. The Python script implements the "eppy" library using the parameters provided by the optimizer. It modifies the building model characteristics, creating IDF objects; than the script runs the EnergyPlus simulation, and reads the results of a single run. The script takes care also of the economical side of the problem by computing the investment cost. The second modeFRONTIER project is then invoked, where the economic parameters are changed in a stochastic manner, the NPV is computed and transferred to the original project. Primary energy and net present value $10^{\text {th }}$ percentile are used as optimization objectives by modeFRONTIER in order to define new designs. The computation workflow is represented in Figure 2 where a little Gaussian shape identifies the input and output of parameters with stochastic distribution while the part enclosed into the dotted line performs the stochastic simulation.

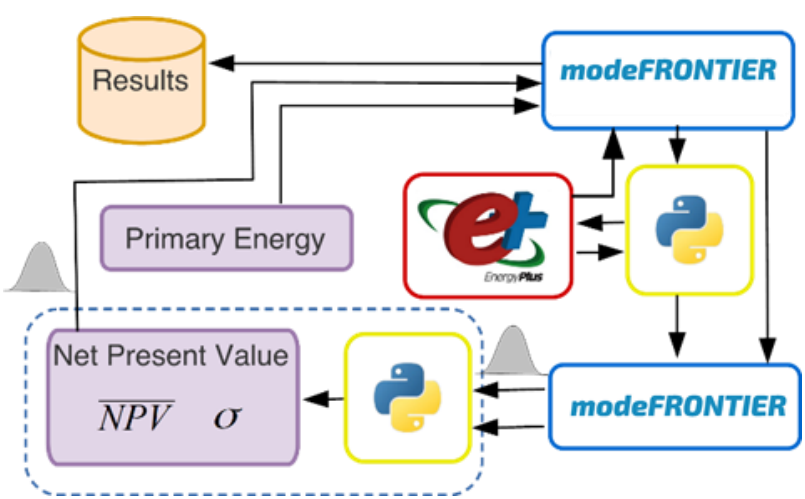

Figure 2: RBDO simulation workflow.

\section{Design choices}

The same optimization parameters identified in Lupato (2018) have been inserted in the optimization loop; in particular, the variables identify refurbishing activities on vertical walls considering different exposition, insulation of roof, floors and ceilings that separate the heated areas from crawl spaces. Three different types of windows have been considered: a double-glass with air gap, a doubleglass with Argon filled gap and a triple-glass with Argon filled gaps. Table 4 reports used glass values.

Table 5 reports the base, lower and higher ranges of overall thermal transmittances for opaque surfaces, along with the insulation layer characteristics. The values of the original building are highlighted in grey.

Ten optimization parameters have been considered, seven variables are related to the opaque surfaces and three are related to transparent ones.

Investment cost are computed taking into account the costs of the material of insulation layers along with the cost of installation. Prices were obtained from the public regional administration price list Prezziario Regionale dei Lavori Pubblici (2017). Window prices were instead acquired from real quotes considering transport and installation costs.

\section{Optimization settings}

Two objectives have been defined for the optimization, specifically the minimization of the primary energy of the building and the maximization of the $10^{\text {th }}$ percentile of the NPV. It is worth noting that the latter objective is a statistical one, with the meaning that $90 \%$ of the solution are expected to have a value greater than the objective. As already pointed out, the choice has been made in order to replicate the decision making of an investor with a lowrisk attitude. The optimization process has been performed using the NSGA II optimization algorithm, starting with an initial Design of Experiments of 24 individuals. The genetic optimization has been performed for 30 generations and the optimization lasted $12 \mathrm{~h} 30 \mathrm{~min}$ on a 12 cores workstation. Since the numerical computation with EnergyPlus and the stochastic optimization have been decoupled the genetic algorithm has been the straightforward choice. However, if the stochastic approach would be extended to parameters affecting directly the simulation with EnergyPlus, other algorithms, such as response factors or the 
modeFRONTIER FAST algorithm (Manzan 2017) would be more appropriate in order to obtain solutions in reasonable time.

\section{Primary energy and conversion factors}

Conversion factors to primary energy were set to 3.167 and 1.084 for electricity and natural gas respectively.

Standard cubic meters of natural gas were calculated considering the lower heating value of natural gas equal to $9.94 \mathrm{kWh} / \mathrm{sm}^{3}$.

\section{Discussion and results analysis}

Optimizations results are reported in Figures 3 to 6 using bubble-plots to present up to four variables. Bubbles diameters are proportional to the external walls thermal transmittance, south and north oriented, that covers most of the heat losses. Bubble colours represent window types that is blue Type 0 , green Type 1 and red Type $2.10^{\text {th }}$ percentile of NPV and primary energy are the axes of the plot.

Figures 3 and 4 refer to optimizations performed with a fixed, but different for each design, initial investment, while Figures 5 and 6 refer to an optimization obtained with the investment treated as a stochastic variable that follows a uniform distribution with a range of $\pm 10 \%$.

The inspection of Figure 3 shows that with low energy footprint the solutions are characterized by high insulation levels, as can be inferred by low circles diameter. When the solutions move towards the right of the abscissa axes the insulation decreases, as can be inferred by the larger diameter of the bubbles. Very interesting is the analysis of window selection. In this case, the most performant window is selected only with low energy solutions with low NPV. However, when the solutions evolve towards high NPV values the optimization selects the less performant one; in this case the lower investments drive the solutions towards lower insulation levels. Window
Type 1 is seldom selected and never for solutions pertaining to the Pareto front. Figure 4 reports the same situation, but for the south façade. In this case, the solution for windows is nearly always the Type 0 , with the highest value of transmittance, but also high solar contribution since the SHGC is the highest.

Figure 5 reports the solutions in the same conditions, but with a stochastic variation of the investment cost. The designs behave in a similar manner than the one already presented. However, it appears that in this case performant windows are selected also for higher values of NPV. This behaviour could be explained considering the fluctuations of the investment cost: if it increases then better solutions are searched in order to compensate, through a greater revenue coming from energy savings, the potential variation in initial investment cost. Again Figure 6 shows that for southern façade the Type 0 window is the preferred one.

Figure 7 presents the comparison between the Pareto front of the solutions related to the north façade. The Pareto front shows how the optimization selects opaque walls transmittance and drives window selection.

Finally, four designs from the Pareto front are compared for each case; they represent the designs with maximum NPV, lower PE, plus two intermediate designs with similar values of NPV and PE, but with different window Type selection. The chosen designs are reported with squares in Figures 3 to 6 and also reported as design Id in Figure 7. Comparing the selection of Ids 518 and 473 for the constant investment case and 427 and 495 for the latter, it is worth noting that when a less performant window is selected the opaque wall structures presents lower thermal transmittance in order to compensate for the higher thermal dispersion from windows.

Table 4: Glass solar properties.

\begin{tabular}{|c|c|c|}
\hline Base & $U_{g}\left[\mathrm{~W} /\left(\mathrm{m}^{2} \mathrm{~K}\right)\right]$ & 5.7 \\
& $\mathrm{SHGC}[-]$ & 0.87 \\
\hline Type 0 & $U_{g}\left[\mathrm{~W} /\left(\mathrm{m}^{2} \mathrm{~K}\right)\right]$ & 1.4 \\
& $\mathrm{SHGC}[-]$ & 0.66 \\
\hline Type 1 & $\left.U_{g}\left[\mathrm{~W} / \mathrm{m}^{2} \mathrm{~K}\right)\right]$ & 1.2 \\
& $\mathrm{SHGC}[-]$ & 0.425 \\
\hline Type 2 & $U_{g}\left[\mathrm{~W} /\left(\mathrm{m}^{2} \mathrm{~K}\right)\right]$ & 0.8 \\
& $\mathrm{SHGC}[-]$ & 0.398 \\
\hline
\end{tabular}

Table 5: Opaque overall thermal transmittances and insulation layers characteristics.

\begin{tabular}{|c|c|cc|cc|ccc|}
\hline $\begin{array}{c}\text { Opaque } \\
\text { Construction }\end{array}$ & $\begin{array}{c}U_{\text {base }} \\
{\left[\mathrm{W} / \mathrm{m}^{2} \mathrm{~K}\right]}\end{array}$ & $\begin{array}{c}U_{w} \max \\
{\left[\mathrm{W} / \mathrm{m}^{2} \mathrm{~K}\right]}\end{array}$ & $\begin{array}{c}U_{\mathrm{w}} \min \\
{\left[\mathrm{W} / \mathrm{m}^{2} \mathrm{~K}\right]}\end{array}$ & $\begin{array}{c}t_{\text {ins }} \min \\
{[\mathrm{cm}]}\end{array}$ & $\begin{array}{c}t_{\text {ins }} \max \\
{[\mathrm{cm}]}\end{array}$ & $\begin{array}{c}\lambda_{\text {ins }} \\
{[\mathrm{W} / \mathrm{m} \mathrm{K}]}\end{array}$ & $\begin{array}{c}\rho_{\text {ins }} \\
{\left[\mathrm{kg} / \mathrm{m}^{3}\right]}\end{array}$ & $\begin{array}{c}C_{\text {ins }} \\
{[\mathrm{J} / \mathrm{kg} \mathrm{K}]}\end{array}$ \\
\hline Wall & 1.51 & 0.490 & 0.139 & 2 & 14 & 0.035 & 25 & 1400 \\
Ceiling & 15.06 & 1.608 & 0.143 & 2 & 25 & 0.036 & 140 & 1030 \\
Roof & 5.86 & 0.811 & 0.214 & 2 & 20 & 0.035 & 25 & 1400 \\
Floor & 0.68 & 1.348 & 0.17 & 2 & 20 & 0.035 & 35 & 1400 \\
\hline
\end{tabular}




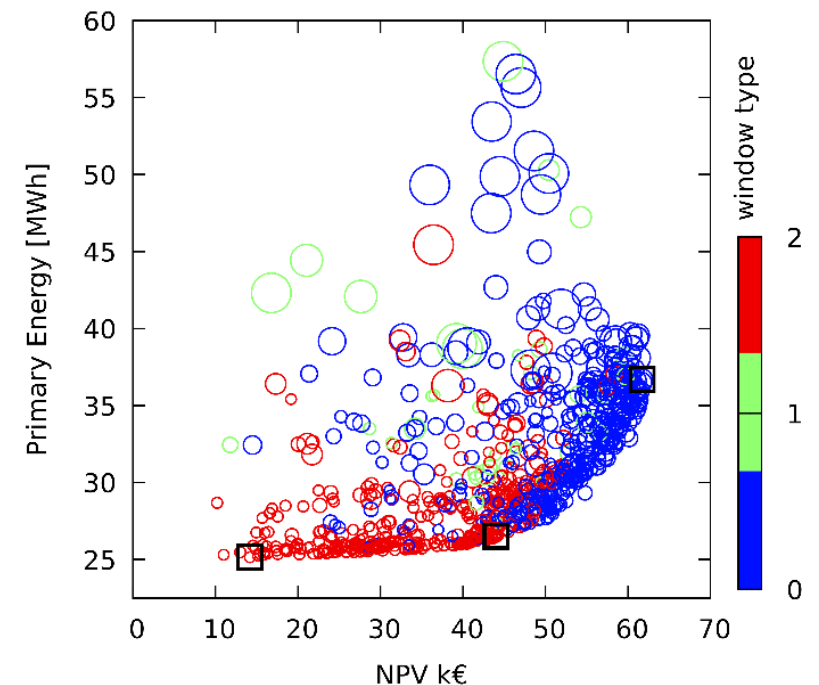

Figure 3: solutions for north wall with constant investment cost.

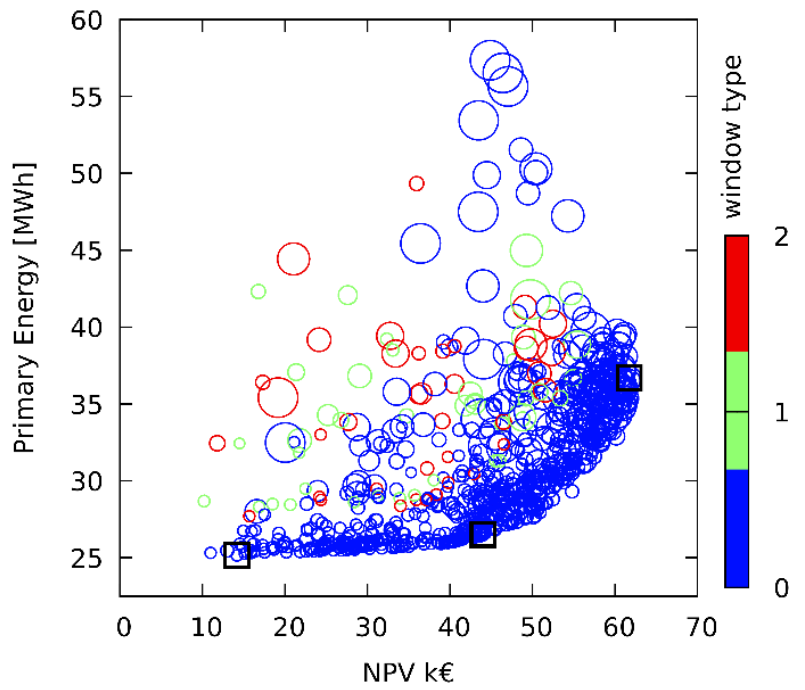

Figure 4: solutions for the southern façade with constant investment cost.

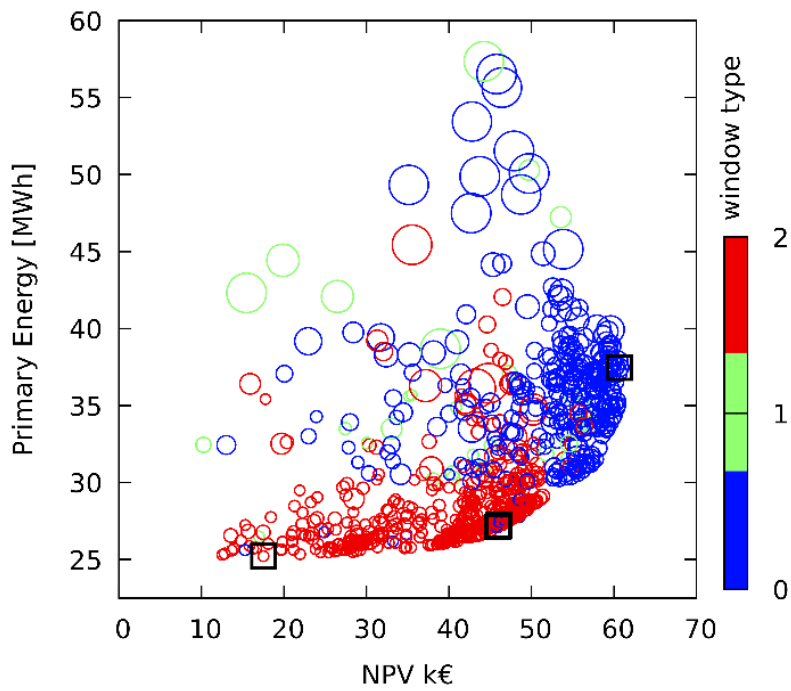

Figure 5: solutions for north wall with stochastic variation of investment cost.

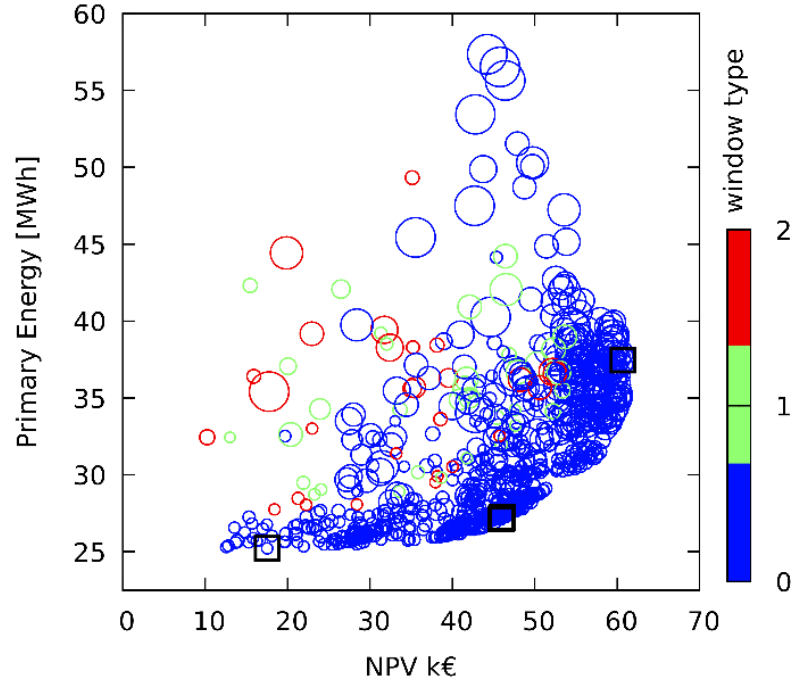

Figure 6: solutions for southern facade with stochastic variation of investment cost.
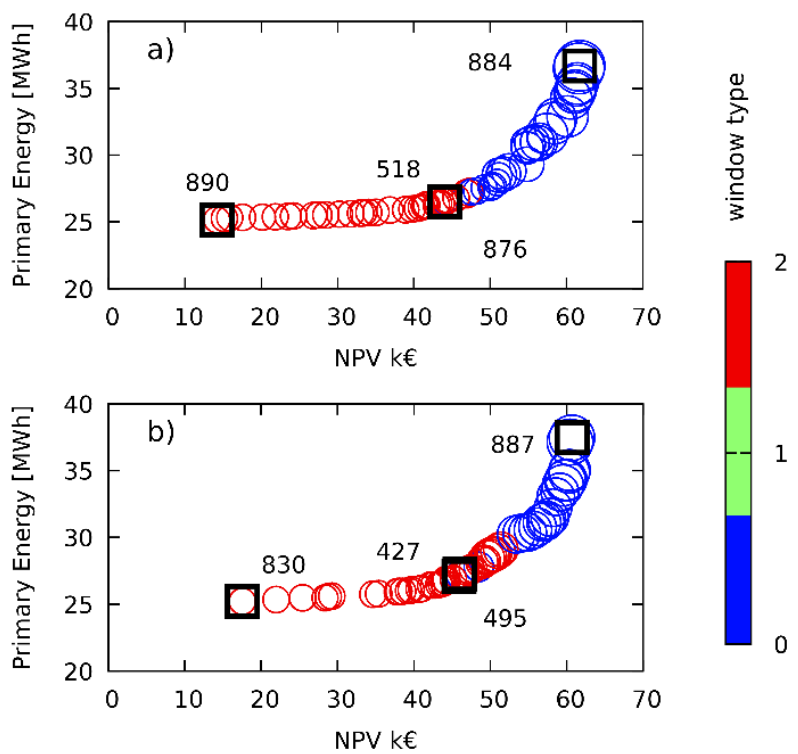

Figure 7: comparison between Pareto Fronts obtained with deterministic investment cost a) and with stochastic distribution $b$ ).

\section{Conclusions}

Building energy reliability-based design optimization for a social building energy refurbishment has been carried out. Uncertainties on economic parameters has been taken into account by assuming a stochastic distribution of the increase of energy prices during building's lifetime. The objectives of the optimization reflect the stochastic nature of the problem by maximizing the NPV with a probability of being exceeded by $90 \%$ in order to reflect the choice of a prudential decision-maker. A subsequent optimization introduced a possible variability of the investment. The optimization leads toward solutions with different choices between north and south facades; furthermore the introduction of variability in investment leads to the selection of more performant windows type respect the fixed case. This represents an important outcome, since the variability of one parameter leads a decision-maker, 
always aware of potential risks, towards conservative solutions. The results show also that the solution can be variegated and depends on the level of acceptable risk. In this paper a $10 \%$ risk has been selected, that is $10 \%$ of the solutions may give NPV values less than the one computed. However, other values can be chosen. The use of Polynomial Chaos Expansion in evaluating the stochastic functions allows, with few evaluations for each design, to determine the percentiles to be used in the optimization. This is an important aspect in case the time for evaluating the objective function becomes time consuming.

Table 6: selected designs for the constant investment.

\begin{tabular}{|c|c|c|c|c|}
\hline ParameterlId. & 890 & 884 & 876 & 518 \\
\hline $\mathrm{U}_{\text {wall }} \mathrm{S}$ & 0.230 & 0.470 & 0.230 & 0.230 \\
\hline $\mathrm{U}_{\text {wall }} \mathrm{N}$ & 0.210 & 0.420 & 0.210 & 0.210 \\
\hline $\mathrm{U}_{\text {wall }} \mathrm{E}$ & 0.210 & 0.420 & 0.210 & 0.210 \\
\hline $\mathrm{U}_{\text {wall }} \mathrm{W}$ & 0.230 & 0.340 & 0.230 & 0.230 \\
\hline$U_{\text {ceiling }}$ & 0.140 & 0.320 & 0.150 & 0.150 \\
\hline $\mathrm{U}_{\text {roof }}$ & 0.240 & 1.350 & 1.350 & 0.970 \\
\hline $\mathrm{U}_{\text {floor }}$ & 0.160 & 0.490 & 0.380 & 0.340 \\
\hline Window1 N & Type3 & Type1 & Type3 & Type1 \\
\hline Window $1 \mathrm{~S}$ & Type 1 & Type 1 & Type1 & Type1 \\
\hline Window $_{2} \mathrm{~S}$ & Type 1 & Type1 & Type 1 & Type1 \\
\hline PE (MWh) & 25.15 & 36.69 & 26.47 & 26.53 \\
\hline NPV (k€) & 14.19 & 61.72 & 43.99 & 44.04 \\
\hline
\end{tabular}

Table 7: selected designs for the stochastic investment.

\begin{tabular}{|l|l|l|l|l|}
\hline PaeameterII & $\mathbf{8 3 0}$ & $\mathbf{8 8 7}$ & $\mathbf{4 9 5}$ & $\mathbf{4 2 7}$ \\
\hline $\mathrm{U}_{\text {wall }} \mathrm{S}$ & 0.230 & 0.470 & 0.230 & 0.240 \\
\hline $\mathrm{U}_{\text {wall }} \mathrm{N}$ & 0.210 & 0.370 & 0.230 & 0.230 \\
\hline $\mathrm{U}_{\text {wall }} \mathrm{E}$ & 0.210 & 0.420 & 0.270 & 0.260 \\
\hline $\mathrm{U}_{\text {wall }} \mathrm{W}$ & 0.230 & 0.470 & 0.230 & 0.230 \\
\hline $\mathrm{U}_{\text {ceiling }}$ & 0.140 & 0.390 & 0.150 & 0.150 \\
\hline $\mathrm{U}_{\text {roof }}$ & 0.280 & 1.350 & 1.350 & 0.970 \\
\hline $\mathrm{U}_{\text {floor }}$ & 0.170 & 0.490 & 0.490 & 0.380 \\
\hline Window1 $\mathrm{N}$ & Type3 & Type1 & Type3 & Type1 \\
\hline Window1 $\mathrm{S}$ & Type1 & Type1 & Type1 & Type1 \\
\hline Window2 $\mathrm{S}$ & Type1 & Type1 & Type1 & Type1 \\
\hline PE $(\mathrm{MWh})$ & 25.22 & 37.47 & 27.11 & 27.23 \\
\hline NPV $(\mathrm{k} €)$ & 17.53 & 60.71 & 45.91 & 46.05 \\
\hline
\end{tabular}

\section{Acknowledgement}

The authors wish to thank the ATER (Azienda Territoriale per l'Edilizia Residenziale di Trieste) for the valuable information.

\section{References}

Ascione F., Bianco N., De Masi R.F., Mauro G.M., Vanoli G.P. (2017). Energy Retrofit of Educational Buildings: Transient Energy Simulations, Model Calibration and Multiobjective Optimization towards Nearly Zero-Energy Performance. Energy and Buildings 144, 303-319.

Cano E., Moguerza J., Alonso-Ayuso A. (2016). A MultiStage Stochastic Optimization Model for Energy
Systems Planning and Risk Management. Energy and Buildings 110, 49-56.

Chari A., Xanthos S., Christodoulou S. (2017). Stochastic Assessment of the Energy Performance of Buildings. Energy Efficiency 10, 1573-1591.

Clarich A., Pediroda V. (2009). Robust Design Applications with modeFRONTIER, Applying NODESIM-CFD Tools. NODESIM-CFD Workshop on Quantification of CFD Uncertainties, Bruxelles, 2009.

Desogus G., Di Pilla L., Mura S., Pisano G.L., Ricciu R. (2013). Economic Efficiency of Social Housing Thermal Upgrade in Mediterranean Climate. Energy and Buildings 57, 354- 360.

Di Giuseppe E., Massia A,, D’Orazio M., (2017) Probabilistic Life Cycle Cost analysis of building energy efficiency measures: selection and characterization of the stochastic inputs through a case study, Procedia Engineering 180, 491-501

Kalsi M., Hacker K., Lewis K. (2001). A Comprehensive Robust Design Approach for Decision Trade-Offs in Complex Systems Design. Journal of Mechanical Design, Vol. 123, No. 1, 1-10.

Kiureghian A. (2005). First and Second-Order Reliability Methods. Chapter 14 in Engineering Design Reliability Handbook, CRC Press, Boca Raton, FL.

Loeven G., Witteveen J., Bijl H. (2007). Probabilistic Collocation: an Efficient Non-Intrusive Approach for Arbitrarily Distributed Parametric Uncertainties. 45th AIAA Aerospace Science Meeting and Exhibit, Reno, Nevada, 2007.

Lupato G., Manzan M., Pezzi A. (2018). The Effect of Climatic Data on Building Performance Optimization. Proceedings of BSO 2018.

Manzan M., Rossi R., Zandegiacomo De Zorzi E., Lupato G. (2016). Genetic Optimization for Economic Feasibility of Refurbishment in Buildings. Energy Procedia 101,145-152.

Manzan M., Clarich A., (2017) FAST energy and daylight optimization of an office with fixed and movable shading devices, Building and Environment, 113, 175 184.

Prada A., Pernigotto G., Baggio P., Gasparella A. (2018). Uncertainty Propagation of Material Properties in Energy Simulation of Existing Residential Buildings: The Role of Buildings Features. Building Simulation 11, 449-464.

Sun S., Kensek K., Noble D., Schiler M. (2016). A Method of Probabilistic Risk Assessment for Energy Performance and Cost Using Building Energy Simulation. Energy and Buildings 110, 1-12. 